\title{
CYP1A1, GSTM1, GSTT1 and TP53 Polymorphisms and Risk of Gallbladder Cancer in Bolivians
}

\author{
Kazuaki Sakai ${ }^{1 *}$, Ernesto Loza ${ }^{2}$, Guido Villa-Gomez Roig ${ }^{2}$, Ryoko Nozaki³, \\ Takao Asai ${ }^{3}$, Toshikazu Ikoma ${ }^{4}$, Yasuo Tsuchiya ${ }^{1}$, Chikako Kiyohara $^{5}$, Masaharu \\ Yamamoto $^{3}$, Kazutoshi Nakamura ${ }^{1}$
}

\begin{abstract}
The Plurinational State of Bolivia (Bolivia) has a high incidence rate of gallbladder cancer (GBC). However, the genetic and environmental risk factors for GBC development are not well understood. We aimed to assess whether or not cytochrome P450 (CYP1A1), glutathione S-transferase mu 1 (GSTM1), theta 1 (GSTT1) and tumor suppressor protein p53 (TP53) genetic polymorphisms modulate GBC susceptibility in Bolivians. This case-control study covered 32 patients with GBC and 86 healthy subjects. GBC was diagnosed on the basis of histological analysis of tissues at the Instituto de Gastroenterologia Boliviano-Japones (IGBJ); the healthy subjects were members of the staff at the IGBJ. Distributions of the CYP1A1 rs1048943 and TP53 rs1042522 polymorphisms were assayed using PCR-restriction fragment length polymorphism assay. GSTM1 and GSTT1 deletion polymorphisms were detected by a multiplex PCR assay. The frequency of the GSTM1 null genotype was significantly higher in GBC patients than in the healthy subjects (odds ratio [OR], 2.35; 95\% confidence interval [CI], 1.03-5.37; age-adjusted OR, 3.53; 95\% CI, 1.29-9.66; age- and sex-adjusted OR, 3.40; 95\% CI, 1.24-9.34). No significant differences were observed in the frequencies of CYP1 A1, GSTT1, or TP53 polymorphisms between the two groups. The GSTM1 null genotype was associated with increased GBC risk in Bolivians. Additional studies with larger control and case populations are warranted to confirm the association between the GSTM1 deletion polymorphism and GBC risk suggested in the present study.
\end{abstract}

Keywords: Gallbladder cancer - genetic susceptibility - CYP1A1 - GSTM1 - GSTT1 - TP53

Asian Pac J Cancer Prev, 17 (2), 781-784

\section{Introduction}

The Plurinational State of Bolivia (Bolivia) lies west of the Andes and has a high incidence of gallbladder cancer (GBC) (Orth and Beger, 2000; Moore et al., 2014). Previous studies reported high incidences of GBC in Chile, Bolivia, and Peru and in confined areas, such as north India (Wistuba and Ganzdar, 2004; Hundal and Shaffer, 2014). However, the factors responsible for GBC pathogenesis among Bolivians are not well understood. Because almost all cancers develop as a result of a complex interplay between environmental and genetic factors, specific factors are likely responsible for the development of GBC in Bolivians.

Previous studies identified risk factors for GBC development in Bolivians. Strom et al. reported that, in addition to race (i.e., Aymara speakers), risk factors for GBC in Bolivians were body mass index, family history of gallstones, typhoid fever infection, and food consumption habits (Strom et al., 1995). However, these well-known environmental risk factors for GBC are not specific to
Bolivians. Asai et al. reported that GBC development in Bolivians was related to genetic and environmental factors, specifically mutations in tumor protein p53 (TP53) and K-ras (Asai et al., 2014). Thus, both environmental and genetic factors are important in GBC development in Bolivians.

Early studies of mechanisms underlying cancer development mainly investigated environmental factors. However, cancer development is affected by both environmental and hereditary factors (Srivastava et al., 2011; Booth et al., 2012; Songserm et al., 2014). Current evidence indicates that gene-environment interaction is important in understanding cancer development, because cancer risk due to environmental risks is modified by mutations of environmental factor-related genes.

We conducted case-control studies to identify genetic risk factors for GBC in Japan (Tsuchiya et al., 2007), Hungary (Kimura et al., 2008), and Chile (Tsuchiya et al., 2010). These studies investigated frequencies of genetic polymorphisms in metabolic detoxification and cell cycle control and found that the presence of

${ }^{1}$ Division of Preventive Medicine, Niigata University Graduate School of Medical and Dental Sciences, ${ }^{3}$ Niigata University of Health and Welfare, Niigata, ${ }^{4}$ Hokuriku University, Kanazawa, Ishikawa, ${ }^{5}$ Department of Preventive Medicine, Graduate School of Medical Sciences, Kyushu University, Fukuoka, Japan, ${ }^{2}$ Instituto de Gastroenterologia Boliviano-Japones, La Paz, Bolivia *For correspondence: zsakai@med.niigata-u.ac.jp 


\section{Kazuaki Sakai et al}

the $\mathrm{G}$ allele of the cytochrome P450 1A1 (CYP1A1) rs 1048943 polymorphism is related to increased risk of GBC in Japanese and Hungarian women. Asai and colleagues (Asai et al., 2014) reported that the development of GBC in Bolivians is associated with both exogenous carcinogens and endogenous mechanisms, thus, this genetic polymorphism may be related to GBC development in Bolivians.

We hypothesized genetic polymorphisms of metabolic detoxification enzymes and a tumor suppressor gene increase GBC risk in Bolivians. In this study, we assessed the associations of genetic polymorphisms of CYP1A1 rs1048943 (a phase I enzyme), glutathione S-transferase mu 1 (GSTM1) and theta 1 (GSTT1) (Phase 2 enzymes), and TP53 rs 1042522 with GBC risk in Bolivians.

\section{Materials and Methods}

\section{Study subjects}

In this case-control study, the cases were 32 patients with GBC (13 men and 19 women; mean age \pm SD, 58.6 \pm 10.6 ) diagnosed by histological examination of tissue at the Instituto de Gastroenterologia Boliviano-Japones (IGBJ), in La Paz, Bolivia. The controls were 86 medical and office staff (33 men, 53 women; mean age \pm SD, 44.0 \pm 12.3 ) working at the IGBJ.

Informed consent was obtained from all subjects, and the study protocol was approved by the ethics committee of the IGBJ and Niigata University of Health and Welfare.

\section{DNA extraction and storage}

Samples $(2 \mathrm{ml})$ of peripheral blood were collected from cases and controls at the IGBJ and used in the DNA assay. Genomic DNA was extracted from each sample using the QuickGene-810 nucleic acid isolation system (Wako Pure Chemical Industries Ltd., Osaka, Japan) and a standard commercial kit (DNA Extractor WB-rapid, Wako Pure Chemical Industries). The extracted DNA samples were dissolved in TE buffer and stored in a freezer at $-80^{\circ} \mathrm{C}$ until genetic polymorphism analyses were performed.

\section{Genotype analysis}

CYP1A1 rs 1048943 polymorphism was analyzed by a polymerase chain reaction-restriction fragment length polymorphism (PCR-RFLP) assay using restriction enzyme BsrDI (Gaspar et al., 2002). GSTM1 and GSTT1 were analyzed by multiplex PCR assay (Eroglu et al., 2015). TP53 rs1042522 polymorphism was analyzed by a PCR-RFLP assay, using the restriction enzyme BstUI (Zając et al., 2014). DNA was amplified using a thermal cycler (PE 9700, Applied Biosystems, Foster City, Ca, USA), with a final reaction volume of $20 \mu \mathrm{L}$. For quality control, all genotyping assays were examined by two authors, who verified that the results were consistent.

\section{Statistical analyses}

Differences in genotypic frequency between the cases and controls were evaluated by using the $\chi^{2}$ test or Fisher's exact test. The Hardy-Weinberg equilibrium (HWE) was tested for each polymorphism by the Pearson's $\chi^{2}$ test among controls. Age-adjusted and age- and sex-adjusted odds ratios (ORs) and 95\% confidence intervals (CIs) were calculated using logistic regression coefficients. All statistical analyses were performed by using STATA version 14 (STATA Corporation, College station, TX). All $\mathrm{P}$ values were two-sided, with those less than 0.05 considered statistically significant.

\section{Results}

Data from 32 cases and 86 controls were analyzed. The distribution of each genotype agreed with the controls in Hardy-Weinberg equilibrium. As expected, the mean age of the groups significantly differed $(58.6 \pm 10.6$ years for cases $v s 44.0 \pm 12.3$ years for controls). The proportion of women was similar in the two groups: $56.2 \%(18 / 32)$ of cases and $61.6 \%(53 / 86)$ of controls.

Table 1 shows the associations of genetic polymorphism of CYP1A1, GSTM1, GSTT1, and TP53 with GBC risk in Bolivians. The frequency of null type GSTM1 was significantly higher among the cases than the controls (OR, 2.35; 95\%CI, 1.03-5.37). The age-adjusted OR (3.53; 95\%CI, 1.29-9.66) and age- and sex-adjusted OR (3.40; 95\% CI, 1.24-9.34) were also significant. However, no significant differences were found for the CYP1A1 rs 1048943, GSTT1, or TP53 rs1042522 polymorphisms.

Table 2 shows the associations of allelic frequencies of CYP1A1 rs1048943 and TP53 rs1042522 polymorphisms with GBC risk. The frequency of the G allele in CYP1A1 was $65.6 \%$ (42/64) among the cases and 69.2\% (119/172) among the controls, a nonsignificant difference. Moreover, there was no significant difference in the frequency of the

Table 1. Associations of Genetic Polymorphis of CYP1A1, GSTM1, GSTT1, and TP53 with Gallbladder Cancer Risk in Bolivians

\begin{tabular}{llcccc}
\hline Gene (rs\#) & Genotype & Controls $(86) \mathrm{n}(\%)$ & Cases(32) n $(\%)$ & OR & 95\% CI \\
\hline CYP1A1 (rs1048943) & A/A & $10(11.6)$ & $1(3.1)$ & 1.00 & \\
& A/G & $33(38.4)$ & $20(62.5)$ & 6.06 & $0.75-51.0$ \\
& G/G & $43(50.0)$ & $11(34.4)$ & 2.56 & $0.30-22.2$ \\
GSTM1 & Non-null & $58(67.4)$ & $15(46.9)$ & 1.00 & 0.380 \\
& Null & $28(32.6)$ & $17(53.1)$ & 2.35 & $1.03-5.37$ \\
GSTT1 & Non-null & $63(73.3)$ & $28(87.5)$ & 1.00 & 0.041 \\
& Null & $23(26.7)$ & $4(12.5)$ & 0.39 & $0.12-1.24$ \\
TP53 (rs1042522) & G/G & $46(53.5)$ & $12(37.5)$ & 1.00 & 0.102 \\
& C/G & $33(38.4)$ & $18(56.3)$ & 2.09 & $0.89-4.92$ \\
& C/C & $7(8.1)$ & $2(6.2)$ & 1.10 & 0.089 \\
\hline
\end{tabular}

OR: odd ratio, $\mathrm{CI}$ : confidence interval 
CYP1A1, GSTM1, GSTT1 and TP53 Polymorphisms and Risk of Gallbladder Cancer in Bolivians Table 2. Associations of Frequencies of CYP1A1 rs1048943 and TP53 rs1042522 Polymorphism with GBC Risk

\begin{tabular}{|c|c|c|c|c|c|c|}
\hline Gene (rs\#) & Allele & Controls $\mathrm{n}(\%)$ & Cases n $(\%)$ & OR & $95 \% \mathrm{CI}$ & $\mathrm{P}$ value \\
\hline \multirow[t]{2}{*}{ CYP1A1 (rs1048943) } & A & $53(30.8)$ & $22(34.4)$ & 1.00 & & \\
\hline & $\mathrm{G}$ & $119(69.2)$ & $42(65.6)$ & 0.85 & $0.46-1.56$ & 0.601 \\
\hline \multirow[t]{2}{*}{ TP53 (rs1042522) } & G & 125 (72.7) & $42(65.6)$ & 1.00 & & \\
\hline & $\mathrm{C}$ & $47(27.3)$ & $22(34.4)$ & 1.39 & $0.75-2.58$ & 0.290 \\
\hline
\end{tabular}

OR: odd ratio, $\mathrm{CI}$ : confidence interval

Table 3. Associations of Combinations of the GSTM1 Null and GSTT1 Null Genotypes with GBC Risk

\begin{tabular}{llccccc}
\hline GSTM1 & GSTT1 & Controls $\mathrm{n}(\%)$ & Cases $\mathrm{n}(\%)$ & OR & 95\% CI & P value \\
\hline Non-null & Non-null & $43(50.0)$ & $13(40.6)$ & 1.00 & & \\
Null & Non-null & $20(23.3)$ & $15(46.9)$ & 2.48 & $1.00-6.18$ & 0.051 \\
Non-null & Null & $15(17.4)$ & $2(6.2)$ & 0.44 & $0.09-2.19$ & 0.316 \\
Null & Null & $8(9.3)$ & $2(6.2)$ & 0.83 & $0.16-4.39$ & 0.823 \\
\hline
\end{tabular}

OR: odd ratio, $\mathrm{CI}$ : confidence interval

$\mathrm{C}$ allele between the cases and the controls.

Table 3 shows the associations of possible combinations of the GSTM1 and GSTT1 genotypes with GBC risk. Because we noted a relationship between null type GSTM1 and increased GBC risk, we studied the relationship of the combination of GSTM1 null and GSTT1 null genotypes with GBC risk. The frequency of the double-null genotype was $6.2 \%(2 / 32)$ among the cases and 9.3\% (8/86) among the controls, a nonsignificant difference.

\section{Discussion}

This case-control study revealed that the GSTM1 null genotype is associated with increased GBC risk in Bolivians. However, cases and controls did not significantly differ in genono significant differences in genotype frequencies of CYP1A1 rs 1048943, GSTT1, or TP53 rs 1042522 were found between the cases and the controls.

A previous study found two key pathways in GBC development: a TP53-inactivation pathway and a K-ras-mutation pathway (Wistuba and Gazdar, 2004). This suggests that the pathogenic mechanisms of GBC cannot be adequately explained by environmental factors and that gene-environment interaction is important in understanding this mechanism.

Although the incidence rate of GBC is high in Bolivia, GBC pathogenesis has not been adequately studied in that population. Although some putative risk factors for GBC in Bolivians have been identified, the mechanism of GBC development cannot be explained by these factors alone. Our recent study suggested that genetic factors were important for GBC development in Bolivians. However, no such factors have been identified.

The present study was designed as a preliminary study of genetic factors associated with GBC in Bolivians. More specifically, we investigated associations of genetic variants for metabolic detoxification and cell cycle control with GBC risk in Bolivians. We chose to focus on these genetic polymorphisms because our previous studies of Japanese and Hungarians yielded evidence of associations between CYP1A1 polymorphism and increased GBC risk. In the present study, presence of the GSTM1 null genotype significantly increased GBC risk. This suggests that an unknown environmental chemical is related to
GBC development and that the process of detoxifying this chemical is important in GBC pathogenesis. In other words, GBC may be more likely to develop among Bolivians with GSTM1 gene mutation.

GSTM1 is involved in expression of glutathione$\mathrm{S}$-transferases (GSTs) and encodes for a class mu GST involved in detoxification of polycyclic aromatic hydrocarbons (Hayes and Pulford. 1995). GSTM1 is located on chromosome 1p13.3 and has high genetic diversity (Pearson et al., 1993). A previous study reported that genetic diversity in GSTM1 was responsible for differences in human susceptibility to drugs, carcinogens, and environmental chemicals (Geisler and Olsham. 2001). Another study found that the GSTM1 null genotype is associated with increased susceptibility to these chemicals and later, increased risk of cancer development (Lee and Christiani. 2010).

Several studies have examined the association between GSTM1 genotype and cancer risk (Wang B et al., 2010; Wang J et al., 2011; Mandegary et al., 2011; Gu et al., 2014), but the findings have been inconsistent, even for cancers of the same tissue. Furthermore, recent studies of the combined effect of GSTM1 and GSTT1 polymorphisms on the development of several diseases yielded inconsistent results (Lemos et al., 2008; Sobti et al., 2008; Piao et al., 2013). Although our data showed that the GSTM1 null genotype increased GBC risk, no combined effect was observed. Nevertheless, to our knowledge this is the first study to show an association between the GSTM1 null genotype and increased GBC risk in Bolivians.

This study had limitations. First, our findings might not have reached conventional levels of statistical significance because the samples of GBC patients and healthy subjects were small. The results may therefore not reflect the actual genetic risk factors for GBC. Thus, our results require confirmation in a study with greater numbers of cases and controls. Second, differences in lifestyle factors, such as smoking and drinking, were not considered in this study. Despite these limitations, our result that the GSTM1 null genotype was associated with increased risk of GBC is not likely to be a chance finding. Furthermore, the association between CYP1A1 polymorphism and GBC risk, which was demonstrated in our previous studies of Japanese and Hungarians, was 
not observed in the present study, perhaps due to ethnic differences between populations. GBC prevalence exhibits marked geographic and ethnic variation; GBC is likely associated with regionally specific risk factors and genetic factors in Bolivians. When environmental risk factors for GBC in Bolivians were revealed by several studies, our finding will be contributed clarification of the mechanism of the development of the cancer.

In summary, the GSTM1 null genotype was associated with increased GBC risk in Bolivians. GSTM1 is a critical detoxifying enzyme. Future case-control studies of the effects of environmental factors on GBC in Bolivians are likely to benefit from our finding regarding the underlying mechanism of GBC development in Bolivians. Although the present results require confirmation in a larger study, the GSTM1 null genotype appears to have a role in GBC development in Bolivians.

\section{Acknowledgements}

We are grateful to Mr. David Kipler for reviewing the language of the manuscript. This study was supported in part by a Grant-in-Aid for scientific Research (C) (2012, \#24590767) from the Japanese Ministry of Education, Science, Sports and Culture.

\section{References}

Asai T, Loza E, Roig GV, et al (2014). High Frequency of TP53 but not K-ras gene mutation in Bolivian patients with gallbladder cancer. Asian Pac J Cancer Prev, 15, 5449-54.

Booth FW, Roberts CK, Laye MJ (2012). Lack of exercise is a major cause of chronic diseases. Compr Physiol, 2, $1143-211$.

Eroglu P, Erkol Inal E, Sag SO, et al (2015). Association analysis of GSTM1,T1 and P1 IIe105Val polymorphism with carpal tunnel syndrome. Clin Rheumatol, 9, 1-7.

Gaspar PA, Kvitko K, Papadópolis LG, et al (2002). High frequency of CYP1A $1 * 2 \mathrm{C}$ allele in Brazilian population. Hum Biol, 74, 235-42.

Geisler SA, Olshan AF (2001). GSTM1, GSTT1, and the risk of squamous cell carcinoma of the Head and Neck: A miniHuGE review. Am J Epidemiol, 154, 95-105.

Gu J, Zou H, Zheng L, et al (2014). GSTM1 null genotype is associated with increased risk of gastric cancer in both eversmokers and non-smokers: a meta-analysis of case-control studies. Tumor Biol, 35, 3439-45.

Hayes JD, Pulford DJ (1995). The glutathione S-transferase supergene family: regulation of GST and the contribution of the isoenzymes to cancer chemoprotection and drug resistance. Crit Rev Biochem Mol Biol, 30, 445-600.

Hundal R, Shaffer EA (2014). Gallbladder cancer: Epidemiology and outcome. Clin Epidemiol, 6, 99-109.

Kimura A, Tsuchiya Y, Lang I et al (2008). Effect of genetic predisposition on the risk of gallbladder cancer in Hungary. Asian Pac J Cancer Prev, 9, 391-6.

Lazcano-Ponce EC, Miquel JF, Muñoz N, et al (2001). Epidemiology and Molecular Pathology of Gallbladder Cancer. CA Cancer J Clin, 51, 349-64.

Lee MS, Su L, Christiani DC (2010). Synergistic effects of NAT2 slow andGSTM1 null genotypes on carcinogen DNA damage in the Lung. Cancer Epidemiol Biomarkers Prev, 19, 1492-7.

Lemos MC, Coutinho E, Gomes L, et al (2008). Combined GSTM1 and GSTT1 null genotypes are associated with a lower risk of papillary thyroid cancer. $J$ Endocrinol Invest, 31, 542-5.

Mandegary A, Rostami S, Alimoghaddam K, et al (2011). Glutathione-S-transferase T1-null genotype predisposes adults to Acute Promyelocytic Leukemia, a case-control study. Asian Pac J Cancer Prev, 12, 1279-82.

Moore LE, Baris DR, Figueroa JD, et al (2011). GSTM1 null and NAT2 slow acetylation genotypes, smoking intensity and bladder cancer risk: results from the New England bladder cancer study and NAT2 meta-analysis. Carcinogenesis, 32, 182-9.

Moore SP, Forman D, Piñeros M, et al (2014). Cancer in indigenous people in Latin America and the Caribbean: a review. Cancer Med, 3, 70-80.

Orth K, Beger HG (2000). Gallbladder carcinoma and surgical treatment. Langenbecks Arch Surg, 385, 501-8.

Pearson WR, Vorachek WR, Xu SJ, et al (1993). Identification of Class-mu Glutathione Transferase gene GSTM1-GSTM5 on Human Chromosome 1p13. Am J Hum Genet, 53, 220-33.

Piao JM, Shin MH, Kim HN, et al (2013). Glutathione-Stransferase (GSTM1, GSTT1) null phenotypes and risk of lung cancer in a Korean population. Asian Pac J Cancer Prev, 14, 7165-9.

Randi G, Franceschi S, La Vecchia C (2006). Gallbladder cancer worldwide. Int J Cancer, 118, 1591-602.

Sobti RC, Kaur P, Kaur S, et al (2008). Combined effect of GSTM1, GSTT1 and GSTP1 polymorphisms on histological subtypes of lung cancer. Biomarkers, 13, 282-95.

Strom BL, Soloway RD, Rios-Dalenz JL, et al (1995). Risk factors for gallbladder cancer. An international collaborative case-control study. Cancer, 76, 1747-6.

Songserm N, Promthet S, Pientong C, et al (2014). Geneenvironment interaction involved in cholangiocarcinoma in the Thai population: polymorphisms of DNA repair genes, smoking and use of alcohol. BMJ Open, 4, 5447.

Srivastava K, Srivastava A, Kumar A, et al (2011). Gallbladder cancer predisposition: a multigenic approach to DNA-repair, apoptotic and inflammatory pathway genes. PLoS One, 6 , 16449.

Tsuchiya Y, Kiyohara C, Sato T, et al (2007). Polymorphism of cytochrome P450 1A1, glutathione S-transferase class mu, and tumor protein p53 genes and the risk of developing gallbladder cancer in Japanese. Clin Biochem, 40, 881-6.

Tsuchiya Y, Baez S, Calvo A, et al (2010). Evidence that genetic variants of metabolic detoxication and cell cycle control are not related to gallbladder cancer risk in Chilean women. Int J Biol Markers, 25, 75-8.

Voho A, Impivaara O, Järvisalo J, et al (2006). Distribution of glutathione S-transferase M1, P1 and T1 genotypes in different age-groups of Finns without diagnosed cancer. Cancer Detect Prev, 30, 144-51.

Wistuba II, Gazdar AF (2004). Gallbladder cancer: Lessons from a rare tumor. Nat Rev Cancer, 4, 695-706.

Wang B, Huang G, Wang D, et al (2010). Null genotype of GSTM1 and GSTT1 contribute to hepatocellular carcinoma risk: Evidence from an update meta-analysis. $J$ Hepatol, 53, 508-18.

Wang J, Jiang J, Zhao Y, et al (2011). Genetic polymorphisms of glutathione S-transferase genes and susceptibility to colorectal cancer: A case-control study in an Indian population. Cancer Epidemiol, 35, 66-72.

Yuan JM, Chan KK, Coetzee GA, et al (2008). Genetic determinants in the metabolism of bladder carcinogens in relation to risk of bladder cancer. Carcinogenesis, 29 1386-93.

Zając A, Smolarz B, Stachowiak G, et al (2014). TP53 and MDM2 polymorphisms and the risk of endometrial cancer in postmenopausal women. Med Oncol, 31, 286. 